\title{
FURTHER EFFECTS OF THE PIGMENT-RESTRICTING GENE, $M$, IN POTATOES: HIDDEN SPOTTED AND SPECTACLED
}

\author{
H. W. HOWARD
}

Plant Breeding Institute, Trumpington, Cambridge

Received 14.xii.63

\section{INTRODUCTION}

IN the cultivated tetraploid potato, Solanum tuberosum $L_{\text {, }}$, two types of coloured tubers can be distinguished. For both types a basic gene, $D$, is necessary. Together with $E, D$ produces pink tubers of colour type I, and together with $R$, pink tubers of colour type 2. In colour type I nearly all the pigmented cells are in the periderm layer; in colour type 2, the periderm cells are without pigment and the pigmented cells are in the phelloderm (Lunden, I937; Howard, 1960).

The pigment-restricting gene, $M$, at least when closely linked to the gene $E$, produces tubers in which the periderm pigment is restricted to areas around the eyes (fig. I $b$ ). Crosses between $R D$ and $E M D$ varieties result in seedlings with tubers of four colour types. These tuber colours are white, uniform pink $(R D)$, splashed pink $(E M D)$ and splashed pink on a uniform pink background (EMRD), (Carson and Howard, I945). The last type (fig. I $c$ ) was designated as " hidden spotted" by Asseyeva (I 93 I).

It was found by Asseyeva (193I) and confirmed by Howard (1962) that the removal of eyes from white-splashed-pigment tubers (in Asseyeva's terminology, "large spotted") resulted in some of the plants which originate from the adventitious buds produced by the
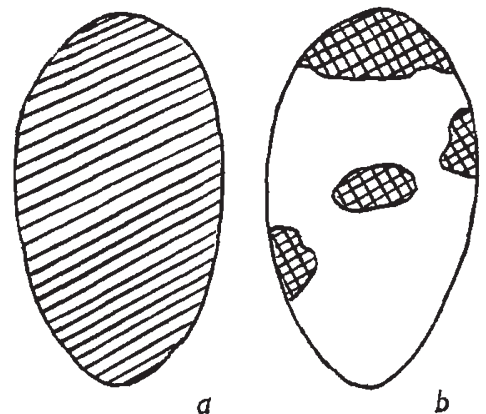

b
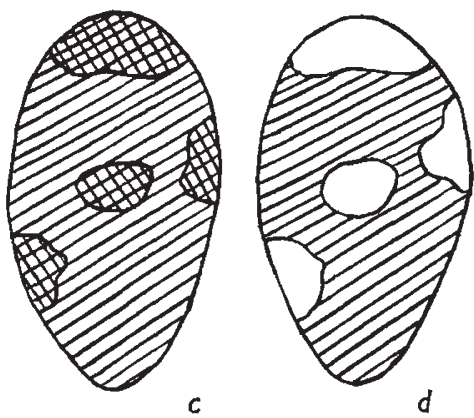

Fig. 1.-Tuber colour types (areas of pigmented phelloderm hatched and of pigmented periderm cross-hatched).

(a) Uniform pink, e.g. Flourball.

(b) White-splashed-pink, e.g. 35/68 (this is the large spotted of Asseyeva, 1931).

(c) Hidden spotted-uniform pink with areas of deeper colour around the eyes, e.g. $\mathrm{R}_{57 / 3}$.

(d) Spectacled-note the areas without pigment around the eyes. 
treated tubers, having white tubers. These white tubers were called "small spotted" by Asseyeva because pigment was still present as very small specks in the lenticels.

This paper considers the transformation as a result of either eyeexcision or X-ray treatment of " hidden spotted " into " spectacled" (fig. Id), a phenomenon which was also observed by Asseyeva (I93I).

\section{FAMILY R57}

The two parents used to produce the family in which there were some seedlings with hidden spotted tubers were $35 / 68$ and Flourball. The clone $35 / 68$, which has white-splashed-pink tubers, was obtained in breeding for blight (Phytophthora infestans) resistance-see Cooper and Howard (1952). Flourball is an old variety with uniform pink tubers of colour type 2 . The family, $R_{57}$, from the cross of these two parents, consisted of I 28 seedlings, of which $5^{6}$ had white tubers, 37 white-splashed-pink, 22 uniform pink and 13 hidden spotted. All 37 of the white-splashed-pink type had pigment in the periderm cells of the tubers and all but one of the 22 uniform pink type had no colour in the periderm. The one exception with a uniform pink periderm arose presumably as a result of a cross-over between $E$ and $M$.

\section{FAMILY P50 (R57/3 $\times$ ULSTER KNIGHT)}

One seedling $\left(\mathrm{R}_{57} / 3\right)$ which produced large tubers of the hidden spotted type, was selected for experiments. The cross of $R_{57 / 3}$ by Ulster Knight (white tubers), family $\mathrm{P}_{50}$, contained 55 seedlings of which I 3 had white tubers, 22 white-splashed-pink, I4 uniform pink and 6 hidden spotted. All the white-splashed-pink tubers had pigment in the periderm cells and all the uniform pink tubers had no pigment in the periderm. The hidden spotted tubers had periderm pigment only in the deeper splashes of colour around the eyes, but none in the other parts. The results for family $\mathrm{P}_{50}$ confirm that $\mathrm{R}_{57 / 3}$, which has hidden spotted tubers, possesses the genes $D, R$ and $E M$.

\section{EYE-EXCISION OF R57/3}

The four plants of $\mathrm{R}_{57 / 3}$ grown from untreated tubers all produced plants which had only hidden spotted tubers (table $1 a$ ). In I962, eyes

TABLE I

(a) Control series $196 \mathrm{I}-7$ h.s. $1962-8$ h.s.; 9 h.s. 1963-9 h.s.; 12 h.s.

(b) Eyes excised $1962-7$ sp.

(c) Plants from spectacled tubers of 1962 1963-5 sp. +12 h.s.; 3 sp. +6 h.s.; 4 sp. + 1o h.s.; 2 sp. +5 h.s.*

* $1963-5$ sp. +12 h.s.; 3 sp. +6 h.s., etc. means that in 1963 one plant had 5 spectacled and 12 hidden spotted tubers; one plant had 3 spectacled and 12 hidden spotted tubers, etc. 
were removed from five tubers of $R_{57 / 3}$, but only one treated tuber produced a plant. All seven tubers formed by this plant were spectacled and not hidden-spotted (table $\mathrm{I} b$ ).

In 1963 four plants were grown from the spectacled tubers of 1962 . Although all four plants had some spectacled tubers, there was a marked reversion to hidden spotted.

\section{X-RAY TREATMENT OF R57/3}

The adventitious buds produced by eye-excised tubers probably originate from single cells (Howard, I96I). Sub-lethal dosages of $\mathrm{X}$-rays on small sprouts may also lead to the growing points being

TABLE 2

Results of $X$-ray treatments ( $3000 \mathrm{r}$ to rose ends of tubers with sprouts about $5 \mathrm{~mm}$. long)

(a) X-rayed rose ends, 1962. 4 out of 5 produced plants.

pot 886-I I h.s.

pot $887-2$ white +6 sp. +8 h.s.

pot $888-$ I sp. +9 h.s.

pot $889-8$ sp. +12 h.s.

(b) 1963 progeny from selected 1962 tubers*

886 h.s. - Io h.s.; I 7 h.s.; 10 h.s.; I sp. + 10 h.s.

887 h.s. - I 3 h.s.; 16 h.s.

888 h.s.-I2 h.s.; 9 h.s.

889 h.s. -I 7 h.s.; 15 h.s.

887 white -6 sp. +4 h.s.; 1 sp. +5 h.s.

887 sp. -20 h.s.; 1 white +3 sp. +4 h.s.

888 sp.-12 h.s.

889 sp. -5 sp.; 5 sp. + I I h.s.; 3 sp. +8 h.s.; 8 sp.

* 889 sp. -5 sp.; 5 sp. + I h h.s.; 3 sp. +8 h.s.; 8 sp. means that four spectacled tubers from pot 889 of 1962 were planted in 1963 . The first plant in 1963 had 5 spectacled, the second 5 spectacled and $I I$ hidden spotted, the third 3 spectacled and 8 hidden spotted, and the fourth plant 8 spectacled tubers.

reduced to single viable cells which then produce a whole new growing point (Howard, 1962). Such X-ray treatment has an advantage over eye-excision in that a much higher proportion of treated tubers produce plants (Heiken and Ewertson, 1962).

Five rose (apical) ends of tubers of $\mathrm{R}_{57 / 3}$ were treated with X-rays in 1962 and four of them produced plants (table 2a). Two of the plants had about equal numbers of spectacled and hidden spotted tubers. This mixture could have been expected because more than one eye of any treated rose-end produced shoots. There were also two white tubers. These were probably immature spectacled tubers in which pigment had not developed in the phelloderm (Howard, I959). This suggestion is supported by the 1963 results-the white tubers produced plants which had a mixture of spectacled and hidden spotted tubers (table $2 b$ ).

Growing on selected tubers from the 1962 plants (table $2 b$ ), showed that the hidden spotted tubers produced plants which had nearly all their tubers of the hidden spotted type (a total of 130 tubers included 
only one spectacled) and that the spectacled tubers, with two exceptions, produced plants which had either only spectacled or a mixture of spectacled and hidden spotted tubers.

\section{DISCUSSION}

(i) Constancy of induced changes

The change from white-splashed-pigment to white brought about by either eye-excision or X-ray treatment was reported by Howard (1962) to be nearly permanent under conditions of mitotic divisions and it was suggested that experiments in which the change was not permanent might be due to misclassification of tubers on the plants from the eye-excised or X-ray treated tubers. Further studies of the lines of $\mathrm{Y}_{30} \mathrm{O} / 8, \mathrm{~V}_{27} \mathrm{~A}$ and $\mathrm{V}_{27} \mathrm{~B}$ with white tubers, which were investigated by Howard ( 1962 ), have given somewhat different results from

TABLE 3

Results from growing white tubers from white-tubered lines of $r_{30} / 8, V_{27} A$ and $V_{27} B$ obtained by eye-excision of splashed tubers

\begin{tabular}{|c|c|c|c|c|c|c|}
\hline \multirow{3}{*}{ Clone } & \multicolumn{3}{|c|}{ Grown in 1962} & \multicolumn{3}{|c|}{ Grown in 1963} \\
\hline & \multirow{2}{*}{$\begin{array}{l}\text { No. of } \\
\text { plants }\end{array}$} & \multicolumn{2}{|c|}{ Total tubers } & \multirow{2}{*}{$\begin{array}{l}\text { No. of } \\
\text { plants }\end{array}$} & \multicolumn{2}{|c|}{ Total tubers } \\
\hline & & white & splashed & & white & splashed \\
\hline $\begin{array}{l}\mathrm{Y}_{30} / 8 \\
\mathrm{~V}_{27} \mathrm{~A} \\
\mathrm{~V}_{27} \mathrm{~B}\end{array}$ & $\begin{array}{l}6 \\
4 \\
6\end{array}$ & $\begin{array}{l}6 \mathrm{I} \\
31 \\
57\end{array}$ & $\begin{array}{l}3 \\
2 \\
8\end{array}$ & $\begin{array}{r}11 \\
8 \\
10\end{array}$ & $\begin{array}{l}73 \\
31 \\
72\end{array}$ & $\begin{array}{r}1 \\
5 \\
16\end{array}$ \\
\hline
\end{tabular}

those previously reported (table 3 ). While for $\mathrm{Y}_{30} / 8$ there is only a low frequency of reversion from white to splashed, for $\mathrm{V}_{27} \mathrm{~B}$ there is apparently a much higher rate. It may be, therefore, that the high reversion rate for spectacled to hidden spotted of $\mathrm{R}_{57 / 3}$ (tables $I C$ and $2 b$ ) is characteristic of this clone and that lower rates might be found for spectacled types obtained by eye-excision or X-ray treatment of other potatoes with hidden spotted tubers.

\section{(ii) Relation between hidden spotted and spectacled}

Even without the results of the eye-excision and X-ray treatment experiments there are two reasons for suggesting that there is a close relationship between hidden spotted and spectacled. First, as Asseyeva (193I) recorded, in the Andigena potatoes where spectacled and hidden spotted colour are common, the two types frequently change over one into the other with vegetative propagation. Secondly, Asseyeva (see table 4) also found that both the cross of hidden spotted by white and the cross of spectacled by white produced families containing plants 
with white, splashed (large spotted in Asseyeva's terminology), uniformly coloured (designated as self-colour by Asseyeva) and hidden spotted tubers, no plants with spectacled tubers being obtained. Similarly, the cross of C.P.C.304S, an Andigena potato with spectacled tubers from the John Innes Institute potato collection, by Ulster Knight

TABLE 4

Segregations in hidden spotted $\times$ white and spectacled $\times$ white crosses

\begin{tabular}{|c|c|c|c|c|c|c|}
\hline \multirow{2}{*}{$\begin{array}{c}\text { Reference } \\
\text { of } \\
\text { Family no. }\end{array}$} & \multirow{2}{*}{ Parents* } & \multicolumn{5}{|c|}{ No. of seedlings with tubers } \\
\hline & & white & $\begin{array}{l}\text { uniform } \\
\text { pigment }\end{array}$ & splashed & $\begin{array}{l}\text { hidden } \\
\text { spotted }\end{array}$ & spectacled \\
\hline \multirow{7}{*}{$\begin{array}{r}\text { Asseyeva } \\
\text { (193I) } \\
\text { Asseyeva } \\
\text { (I93I) } \\
\text { Asseyeva } \\
{ }^{(1931)} \\
\mathrm{P}_{50}{ }^{2} . \\
\mathrm{Ni} 8 .\end{array}$} & Kanzler (h.s.) & & & & & \\
\hline & $\times$ Furstenkron (wh.) & 57 & 28 & $3^{8}$ & 5 & 0 \\
\hline & $\times$ Furstenkron (wh.) & 6 & 14 & 5 & 8 & 0 \\
\hline & $\begin{array}{c}\text { Columbia S.A.303 (sp.) } \\
\times \text { Furstenkron (wh.) }\end{array}$ & & & & & \\
\hline & $\begin{array}{l}\times \text { Furstenkron (wh.) } \\
\mathrm{R}_{57 / 3 \text { (h.s.) }}\end{array}$ & 34 & 20 & 30 & I 4 & 0 \\
\hline & $\begin{array}{l}\quad \times U \dot{U} \text {. Knight(wh.) } \\
\text { C.P.C.304S (sp.) }\end{array}$ & 13 & 14 & 22 & 6 & o \\
\hline & ×Ũ. Knight (wh.) & 33 & 30 & 25 & I6 & 3 \\
\hline
\end{tabular}

* h.s. $=$ hidden spotted; sp. $=$ spectacled; wh. $=$ white tubers

(white tubers) contained only three plants with spectacled tubers but many with either splashed, uniformly coloured or hidden spotted tubers (family $\mathrm{Nr} 8$ in table 4 ).

\section{(iii) Action of the gene $M$}

In the skin (periderm plus phelloderm) of the tubers of the cultivated tetraploid potato, the production of anthocyanin pigments is determined by an interaction between the genes, the conditions found in the cells of different tissues and also on the conditions found in cells of the same tissue in different places (i.e. near an eye or away from an eye). For example, the genes $D$ and $R$ can produce pigment only in phelloderm but not in periderm or cortex cells.

It was suggested by Howard (1962) that the action of the $M$ gene is to inhibit in areas away from the eyes, the pigment formation in the periderm cells brought about by the genes $D$ and $E$. Also, because the genotype DREM usually produces the phenotype hidden spotted, $M$ would appear to be without any effect on pigment formation in the phelloderm cells brought about by the genes $D$ and $R$. The conversion by eye-excision or X-ray treatment of hidden spotted into spectacled, and not into uniformly pigmented, suggests, however, that the action of $M$ is more complex.

Howard ( 1962 ) suggested that plants with white tubers were obtained as a result of eye-excision from splashed (DEM) tubers when 
the adventitious buds on the treated tubers arose from a cell in which $M$ had had its inhibiting effect (fig. $2 a$, cells in region B of the cortex). Extending this simple hypothesis to the conversion of hidden spotted into spectacled (fig. $2 b$ ) it has to be assumed that, while cells in region $\mathrm{B}$ can produce pigment when they are situated in the phelloderm of the original hidden spotted tuber, the phelloderm cells of the tubers produced by the plants originating from adventitious buds in region $\mathrm{B}$ of eye-excised tubers can produce pigment in region B but not in region A. An alternative explanation is that $M$ inhibits pigment formation in phelloderm cells near the eyes in both hidden spotted and spectacled tubers. In hidden spotted tubers this lack of pigment in the phelloderm cells near the eyes may not be easily observed

(a) splashed

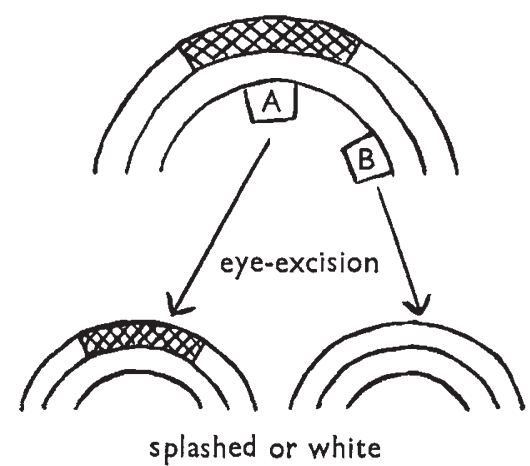

(b) hidden spotted

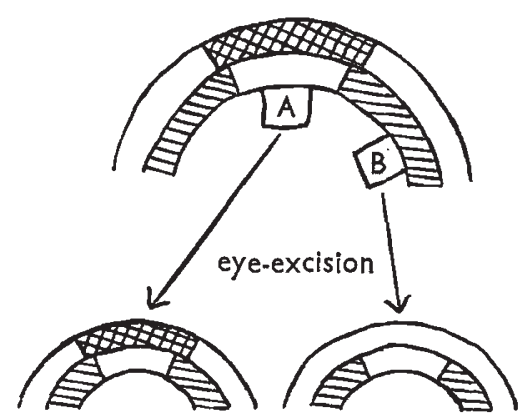

hidden spotted or spectacled

Fig. 2.-Diagrams of sections of tubers to illustrate effects of eye excision on (a) splashed and $(b)$ hidden spotted tubers. Pigmented parts of periderm (outer layer of skin) cross-hatched and of phelloderm (internal to periderm) hatched. It is suggested that adventitious buds may originate in either positions A or B of the cortex.

because of the pigment in the periderm cells or because $D E$ genotypes do have pigment formation in some cells internal to the periderm. In fig. $2 b$ it has been assumed, although there is no direct evidence for it, that in hidden spotted (DREM) there are few or no pigmented cells in the phelloderm beneath the pigmented areas of periderm near the eyes.

(iv) Nuclear or cytoplasmic control of differentiation

Mainly because the genes $E$ and $M$ are in the same chromosome and closely linked, Howard ( 1962 ) suggested that the differentiation of cells by the action of the gene $M$ into those capable of producing anthocyanin pigments and those in which pigmentation was inhibited could be due to either a change in the chromosome carrying the genes $E$ and $M$ or to a change in the cytoplasm. If, as now seems probable, $M$ also affects anthocyanin production due to genes $D$ and $R$, then it seems more likely that the change inhibiting pigment formation is in the cytoplasm. This would agree with the suggestion of Mather and Jinks (1958) that " somatic development and differentiation depend 
characteristically on cytoplasmic change" and that changes in the nuclei, although they may occur during development, " are secondary and not the prime cause of differentiation ". It was found by Howard (1962) that plants from the white tubers obtained from eye-excision of splashed tubers, when crossed with a white-tubered variety, gave progenies with a similar proportion of seedlings with splashed tubers to those obtained from the cross of plants from untreated splashed tubers by the same white parent. This readjustment of the cytoplasm during sexual reproduction agrees also with the postulates of Mather and Jinks.

\section{(v) Spectacled in diploid cultivated pototoes}

In the diploid cultivated potatoes spectacled tubers are also found (Dodds and Paxman, I962). The spectacled genotype is the heterozygote $I i^{s p}$, where the genotypes $I I$ and $I i$ have uniformly coloured tubers and the genotypes $i i^{s p}$ and $i i$ have white tubers. Howard (196o) equated the gene $I$ in the diploid cultivated potatoes with $D$ in the tetraploids. Since $M$ in the tetraploids is linked to $E$ and not to $D$, there appears to be a difference between the genetic determination of spectacled in the tetraploids and that in the diploids from which they were derived. It may be, however, that not all spectacled tetraploid potatoes have the same genotype and that a gene similar to $i^{s p}$ exists in the Andigena potatoes.

\section{SUMMARY}

I. The cross between a potato with white-splashed-pink tubers in which the pigment is in the periderm cells $(D E M)$ and a potato with uniform pink tubers in which the pigment is in the phelloderm cells $(D R)$ produces seedlings which have white, splashed pink $(D E M)$, uniform pink $(D R)$ or hidden spotted (DREM) tubers.

2. Removal of eyes from a hidden spotted tuber results in plants originating from the adventitious buds on the treated tuber producing spectacled tubers.

3. X-ray treatment of hidden spotted tubers also leads to plants with spectacled tubers.

4. The change by eye-excision or X-ray treatment of hidden spotted to spectacled tubers is analogous to the change from splashed to white tubers.

5. Under conditions of vegetative reproduction the spectacled tubers gave rise to plants which also had some spectacled tubers but there was a marked reversion to hidden spotted.

6. It is suggested that, in addition to inhibiting pigment formation in the periderm in areas away from the eyes, the gene $M$ also inhibits pigment formation in the phelloderm in areas around the eyes.

7. It is probable that the effect of the gene $M$ is by way of the cytoplasm and that this explains the persistence under vegetative reproduction of the change from splashed to white and from hidden spotted to spectacled. 


\section{REFERENCES}

AsseYeVA, T. 1931. Bud mutations in the potato. Bull. appl. Bot., Leningrad, 27, 135-217.

GARSON, G. P., AND HOWARD, H. W. 1945. Note on the inheritance of the King Edward type of colour in potatoes. F. Genet., 46, 358-36o.

COOPER, J. P., AND HOWARD, H. W. 1952. The chromosome numbers of seedlings from the cross Solanum demissum $\times$ tuberosum backcrossed by $S$. tuberosum. $\mathcal{F}$. Genet., 50, 511-521.

DODDs, K. S., AND PAXMAN, G. J. 1962. The genetic system of cultivated diploid potatoes. Evolution, $16,154-167$.

HEIKEN, A., AND EWERTSON, G. 1962 . The chimerical structure of a somatic Solanum mutant revealed by ionizing irradiation. Genetica, 33, 88-94.

HOWARD, H. W. 1959. Experiments with a potato periclinal chimera. Genetica, 3o, 278-291.

HOWARD, H. W. 1960. Potato cytology and genetics, 1952-59. Bibliogr. genet., 19, 87-216.

HowARD, H. W. 1961. An octoploid potato from eye-excision experiments. $\mathcal{J}$. Hered., 52, 191-192.

HOWARD, H. W. 1962. Experiments with potatoes on the effect of the pigmentrestricting gene, $M$. Heredity, 17 , 145-1 56 .

LUNDEN, A. P. 1937. Arvelighetsundersokelser i potet. Meld. Norg. LandHøisk, 20, $I-156$.

Mather, K., AND JINKs, J. L. 1958. Cytoplasm in sexual reproduction. Nature, Lond., I82, I I88-I 190. 